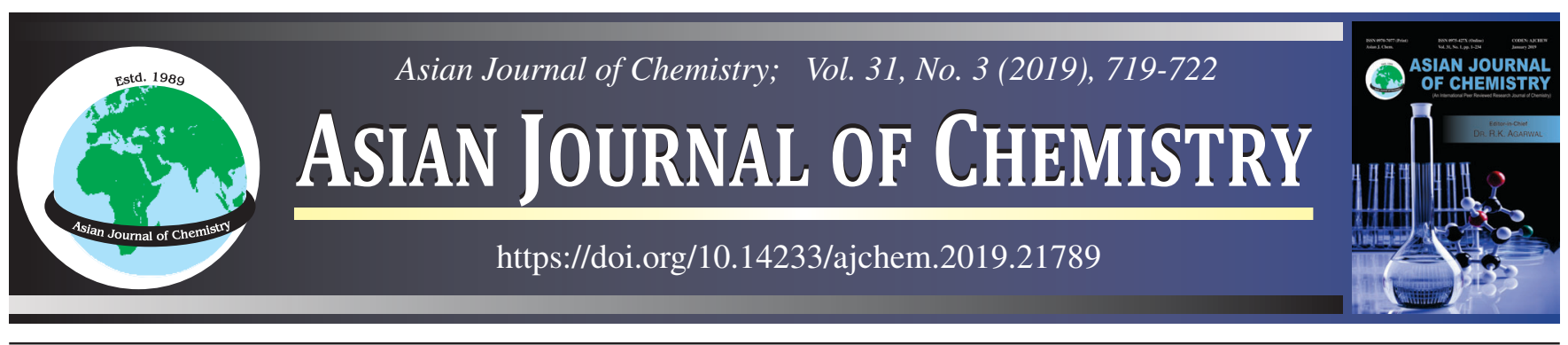

\title{
Oxidative Stress Status in Sera and Saliva of Type 2 Diabetic Iraqi Patients with and without Proliferative Diabetic Retinopathy
}

\section{Hathama Razooki Hasan ${ }^{1, *}$, Nuha Nihad A. Aburahma ${ }^{1}$ and Abdul Kareem A. AL-Kazaz ${ }^{2}$}

${ }^{1}$ Department of Chemistry, College of Science, University of Baghdad, Baghdad, Iraq

${ }^{2}$ Department of Biotechnology, College of Science, University of Baghdad, Baghdad, Iraq

*Corresponding author: E-mail: hathamahasan@scbaghdad.com; hathama2012@gmail.com

Received: 1 November 2018

Accepted: 14 December 2018;

Published online: 31 January 2019;

AJC-19275

The present study aimed to look for the differences in the oxidative stress status in sera and saliva samples of type 2 diabetic Iraqi patients with and without proliferative diabetic retinopathy. As well as to look for the possibility whether this status can be measured in saliva as an alternative sample to that of serum, hence to achieve that total oxidant status, total antioxidant status and oxidative stress index were measured in both sera and saliva samples of two groups of patients with type 2 diabetes mellitus and the healthy individuals. Upon the comparison between patients without proliferative diabetic retinopathy and the control sample the results showed presence of a significant increase $(\mathrm{p}<0.05)$ of total oxidant status and oxidative stress index in sera and saliva samples, while there was a significant decrease $(\mathrm{p}$ $<0.05$ ) in total antioxidant status of sera and saliva samples. Meanwhile when the comparison was done between patients with proliferative diabetic retinopathy and those without proliferative diabetic retinopathy, a significant increase $(\mathrm{p}<0.05)$ in both salivary total oxidant status and oxidative stress index was observed with a significant decrease $(\mathrm{p}<0.05)$ in sera and salivary total antioxidant status were found in the proliferative diabetic retinopathy patients group.

Keywords: Oxidative stress index, Proliferative diabetic retinopathy, Type 2 diabetes mellitus, Iraqi patients.

ᄂ _ - _ - - - - - - - - - - - - - - - - - - - - - - - - - -

\section{INTRODUCTION}

Diabetic retinopathy is diabetic eye disease is one of the most common microvascular complications of diabetes and a leading cause of vision loss, it progresses from mild to severe stages and it happens when blood vessels in the retina leak, or become blocked due to prolonged high blood glucose levels (hyperglycemia) [1]. Proliferative diabetic retinopathy (PDR), the most advanced level of diabetic retinopathy, occurs when there is sufficient retinal ischemia that triggers the formation of fragile new blood vessels (neovascularization), which then leak blood into retina and vitreous [2].

Many studies [3-6] suggested a role of oxidants and antioxidants parameters in diabetes mellitus, these studies were carried out in different countries and populations on serum samples only where individual oxidants such as malondialdehyde levels and antioxidants such as superoxide dismutase were measured. In this study, we carried in our laboratory [7] the oxidant, antioxidant status and oxidative stress index (OSI) were evaluated in serum and saliva samples of type 2 diabetic Iraqi patients with proliferative diabetic retinopathy (PDR) and without any diabetic complications.

\section{EXPERIMENTAL}

The participants of the current study were the same participants of our previous study. The serum and unstimulated whole, mixed-saliva samples which were collected as previously mentioned [7] were analyzed for level of total oxidant status (TOS), total antioxidant status (TAS) and oxidative stress index (OSI). Both serum and saliva samples were stored frozen at $-20^{\circ} \mathrm{C}$ in polyethylene tubes until they were used for the assay. The study protocol was approved by the Ethics Committee of the College of Science, University of Baghdad, Baghdad, Iraq.

Erel's methods were used to determine both TOS and TAS ( $\mu \mathrm{mol} \mathrm{H}_{2} \mathrm{O}_{2}$ equiv./L) [8] and TAS (mmol uric acid equiv./L) [9] in serum and saliva samples. The oxidative stress index (OSI) which is an indicator of degree of oxidative stress [10] was calculated as follows:

This is an open access journal, and articles are distributed under the terms of the Creative Commons Attribution-NonCommercial-ShareAlike 4.0 (CC BY-NC-SA 4.0) International License which allows readers to freely read, download, copy, distribute, print, search, or link to the full texts of its articles and to use them for any other lawful non-commercial purpose as long as the original source is duly acknowledged. 


$$
\text { OSI (arbitrary unit })=\frac{\operatorname{TOS}\left(\mu \mathrm{mol} \mathrm{H}_{2} \mathrm{O}_{2} \text { Eq./L }\right)}{\text { TAS }(\mu \text { mol uric acid Eq./L })} \times 100
$$

Statistical analysis was carried out using the program Statistical Package for the Social Science (SPSS for windows, version 22). The differences between groups were tested by one-way ANOVA followed by Tukey analysis to test the differences between groups and the P-value was considered significant if it was $<0.05$.

\section{RESULTS AND DISCUSSION}

Oxidative stress is one of the parameters which was studied in serum of different types of diabetes mellitus by measuring individual oxidant and antioxidant parameters. Determination of TOS and TAS suggested to be better indicator of the presence of OSI, its use is likely to be more important than TAS and TOS values [11]. Therefore, in the current study oxidative stress status were measured using TOS and TAS in serum and saliva samples of the Iraqi patients and the results are illustrated in Table-1.

Upon the comparison between patients without PDR and the control sample, Table- 1 results show that a highly significant increase $(p<0.01)$ of TOS with a significant decrease of TAS $(p<0.05)$ is present in the serum sample. At the same time, there is a highly significant decrease $(\mathrm{p}<0.01)$ in serum TAS in the patients group with PDR compared to patients without PDR (Table-1).

The results of present study are in accordance with different studies carried only on serum such as a study by Saha et al. [6] showed that a significantly higher plasma TOS level and significantly lower plasma TAS was observed in diabetic patients compared to controls. Rani and Mythili [5] showed that there was a significant decrease in the TAS among type 2 diabetes patients and significant increase in their malondialdehyde levels (which was used as an indicator of increased oxidative stress) in comparison to healthy controls. It also agrees with a study done by Joseph et al. [4], who reported that serum TAS was significantly lower in black South African type 2 diabetes mellitus patients compared to a matched control group. Ganjifrockwala et al. [3] also showed that there was a significant increase in oxidative stress and significant decrease in total antioxidant levels in South African type 2 diabetes mellitus patients compared with controls. The serum results were also in accordance with the results obtained by Beyazyildiz et al. [12] study on Turkish type 2 DM patients, which showed a significant increase in serum TOS levels but a significant decrease in serum TAS levels in type 2 patients without diabetic retinopathy compared to the control sample. Moreover, a significant decreased serum TAS levels was found on Turkish type 2 diabetic patients with PDR compared to those without PDR using the same colorimetric method as described by Erel $[8,9]$. The results of the present study were in accordance with study in Japan conducted by Naruse et al. [13] who reported that progression of diabetic retinopathy is linked to an increase in the oxidative stress and a decrease in antioxidative level.

Retina is most tissue prone to oxidative stress damage due to its rich polyunsaturated fatty acids content, meanwhile it uses more oxygen than any other tissue in the body [14]. Hyperglycemia can induce abnormal metabolism which results in over-production of free radicals and then leads to oxidative stress, that results in damages of the tissues in and around retinal vessels, ultimately resulting in proliferative diabetic retinopathy. Moreover, the damage caused by oxidative stress keeps on for a long time, even after the level of blood glucose has returned to its normal level [15].

Oxidative stress is an imbalance between free radicals formation and their scavenging (antioxidant system) that has been demonstrated as an increased production of pro-oxidative free radicals and/or diminished antioxidant defenses in the body [16]. Blood contains many antioxidants that act to neutralize ROS, or prevent the release of ions responsible for initiating lipid peroxidation [17]. Merhan et al. [18] reported that in case of inflammation and hyperglycemia, antioxidant defense gets weakens and the increased reactive oxygen species leads to oxidative stress.

Regarding saliva, a significant increase $(\mathrm{p}<0.05)$ is obvious in salivary TOS with a significant decrease $(\mathrm{p}<0.05)$ in salivary TAS of patients without PDR compared to control (Table-1). While when compared the results of patients with PDR and those without PDR, a significant increase $(\mathrm{p}<0.05)$ in salivary TOS is clear. At the same time, there is a highly significant decrease $(\mathrm{p}<0.01)$ in saliva of TAS in PDR patients group compared to those without PDR (Table-1). As far as saliva is concerned, a study in Spain by Arana et al. [19] through measurements activity of some salivary antioxidant enzymes (glutathione peroxidase and glutathione reductase) showed that there was an increase in salivary oxidative stress parameters in patients with type 2 diabetes.

The results of present study is confirmed by the calculation of OSI (Fig. 1) which is an indicator of the degree of oxidative

\begin{tabular}{|c|c|c|c|c|c|c|c|c|c|}
\hline \multicolumn{10}{|c|}{$\begin{array}{c}\text { TABLE-1 } \\
\text { OXIDATIVE STRESS STATUS (MEAN } \pm \text { SD) IN SERUM AND SALIVA SAMPLES OF ALL STUDIED GROUPS }\end{array}$} \\
\hline \multirow[b]{2}{*}{ Groups } & \multirow[b]{2}{*}{$\begin{array}{c}\text { Age } \\
\text { (years) }\end{array}$} & \multicolumn{4}{|c|}{ Serum } & \multicolumn{4}{|c|}{ Saliva } \\
\hline & & $\begin{array}{l}\text { TOS }(\mu \mathrm{mol} \\
\left.\mathrm{H}_{2} \mathrm{O}_{2} \mathrm{Eq} / \mathrm{L}\right)\end{array}$ & $\mathrm{P}$-value & $\begin{array}{c}\text { TAS (mmol } \\
\text { uric acid } \\
\text { Eq/L) }\end{array}$ & P-value & $\begin{array}{c}\text { TOS }(\mu \mathrm{mol} \\
\mathrm{H}_{2} \mathrm{O}_{2} \\
\mathrm{Eq} / \mathrm{L})\end{array}$ & P-value & $\begin{array}{c}\text { TAS (mmol } \\
\text { uric acid } \\
\text { Eq/L) }\end{array}$ & P-value \\
\hline Control $(n=30)$ & $\begin{array}{c}50.75 \pm 4.95 \\
(44-59)\end{array}$ & $\begin{array}{c}35.84 \pm 10.15 \\
(21.4-55)\end{array}$ & & $\begin{array}{l}12.65 \pm 0.803 \\
(10.7-14.29)\end{array}$ & & $\begin{array}{l}1.22 \pm 0.743 \\
(0.31-2.95)\end{array}$ & & $\begin{array}{c}11.88 \pm 0.638 \\
(10.2-13.1)\end{array}$ & \\
\hline $\begin{array}{l}\text { Patients without } \\
\text { PDR }(\mathrm{n}=35)\end{array}$ & $\begin{array}{l}55.1 \pm 7.29 \\
(41-68)\end{array}$ & $\begin{array}{l}60.29 \pm 17.85 \\
(24.5-80)\end{array}$ & $0.0001^{\mathrm{a} * *}$ & $\begin{array}{l}11.51 \pm 1.01 \\
(9.57-13.43)\end{array}$ & $0.023^{\mathrm{a} *}$ & $\begin{array}{l}2.58 \pm 1.44 \\
(0.44-4.4)\end{array}$ & $0.020^{\mathrm{a}} *$ & $\begin{array}{c}10.28 \pm 1.52 \\
(8-12.56)\end{array}$ & $0.014^{\mathrm{a} *}$ \\
\hline $\begin{array}{l}\text { Patients with } \\
\text { PDR }(\mathrm{n}=60)\end{array}$ & $\begin{array}{c}57.34 \pm 8.79 \\
(40-78)\end{array}$ & $\begin{array}{c}61.34 \pm 18.6 \\
(26.46-90)\end{array}$ & 0.972 & $\begin{array}{c}10.14 \pm 1.76 \\
(6-11.96)\end{array}$ & $0.002^{\mathrm{b} * *}$ & $\begin{array}{c}3.67 \pm 1.92 \\
(0.78-6.89)\end{array}$ & $0.041^{\mathrm{b} *}$ & $\begin{array}{c}8.05 \pm 2.23 \\
(4.4-11.45)\end{array}$ & $0.0001^{\mathrm{b} * *}$ \\
\hline
\end{tabular}

${ }^{a}$ Patients without PDR $v s$. control; ${ }^{b}$ Patients with PDR $v s$. patients without PDR; **The difference is highly significant at $\mathrm{p}<0.01 ; *$ The difference is significant at $\mathrm{p}<0.05$. 


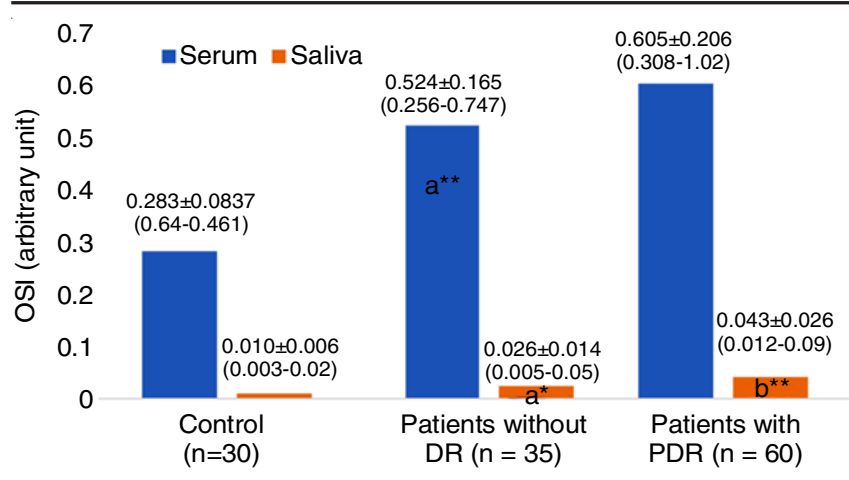

Fig. 1. Mean value \pm SD of serum and salivary oxidative stress index of all studied groups

stress (OSI) that serves as an element of balance which reflects the accurate degrees of imbalance of oxidative stress towards the antioxidant status [10].

Retina is particularly susceptible to oxidative stress because of its high energy demands and exposure to light. Diabetic retinopathy is an eye disorder affecting the human retina due to prolonged hyperglycemia which causes defects in metabolic pathways in relation to the affected antioxidant systems, this increases the production of reactive oxygen species at the retinal level which finally worsens the diabetic complication [20]. Accumulation of reactive oxygen species contributes to the pathogenesis of diabetic retinopathy as well as to the resistance of diabetic retinopathy to reverse even after good glycemic control is achieved condition known as metabolic memory phenomenon $[21,22]$. Chronic oxidative stress in case of diabetic not only creates a vicious cycle of damage to membrane lipids, cell's proteins, nucleic acids as well as disrupting cellular homeostasis, it also amplifies ROS production by activating other metabolic pathways including inflammation, polyol pathway, protein kinase $\mathrm{C}$ pathway (PKC), accumulation of advanced glycation end products (AGEs), and the flux of hexosamine pathway which are involved in the development of diabetic retinopathy. All of these mechanisms appear to be associated with mitochondrial over production of reactive oxygen species (ROS) which are known to promote the breakdown of bloodretinal barrier and to alter retinal blood flow [23-25].

To check the possibility of using saliva as a sample of analysis instead of serum, a Pearson correlation was calculated between the variation in oxidative stress status profile in saliva with serum samples. The most obvious noticed results from Table-2 indicated the presence of a strong correlation (perfect positive correlation) between the changes in TOS, TAS and OSI in serum and saliva of all present studied groups.

\section{TABLE-2}

PEARSON CORRELATION BETWEEN SERUM AND SALIVA PROTEIN PROFILE OF PATIENTS T2DM WITH AND WITHOUT PDR GROUPS

\begin{tabular}{cccc}
\hline Parameters & Control $(\mathrm{n}=30)$ & $\begin{array}{c}\text { Patients without } \\
\text { PDR }(\mathrm{n}=35)\end{array}$ & $\begin{array}{c}\text { Patients with } \\
\text { PDR }(\mathrm{n}=60)\end{array}$ \\
\hline TOS & $0.949^{* *}$ & $0.821^{* *}$ & $0.836^{* *}$ \\
TAS & $0.938^{* *}$ & $0.895^{* *}$ & $0.550^{* *}$ \\
OSI & $0.925^{* *}$ & $0.854^{* *}$ & $0.646^{* *}$ \\
\hline
\end{tabular}

**Correlation is significant at the 0.01 level (2-tailed)

\section{Conclusion}

The differences in the oxidative stress status in serum and saliva samples of type 2 diabetic Iraqi patients with and without PDR support the possibility of that oxidative stress plays a vital role in the development and pathogenesis of type 2 diabetic. The decreased TAS and increased TOS and OSI seem to be among biochemical parameters which predict the longterm complications such as PDR. The present study results also indicate that hyperglycemia seems to affect equally both serum and saliva TAS values in the PDR. Based on correlation results (Table-2), one can conclude that saliva may be used as alternative fluid to serum for measurement of TOS and TAS in the present study.

\section{CONFLICT OF INTEREST}

The authors declare that there is no conflict of interests regarding the publication of this article.

\section{REFERENCES}

1. D. Cavan, L. Makaroff, J. Da Rocha Fernandes, M. Sylvanowicz, P. Ackland, J. Conlon, D. Chaney, A. Malhi and J. Barratt, Diabetes Res. Clin. Pract., 129, 16 (2017); https://doi.org/10.1016/j.diabres.2017.03.023.

2. D.S.W. Ting and T.Y. Wong, Lancet, 389, 2165 (2017); https://doi.org/10.1016/S0140-6736(17)31194-7.

3. F.A. Ganjifrockwala, J. Joseph and G. George, J. Endocrinol. Metabol. Diab. South Africa, 22, 21 (2017); https://doi.org/10.1080/16089677.2017.1324590.

4. J.T. Joseph, F. Ganjifrockwala and G. George, Int. J. Diabetes Dev. Ctries., 31, 75 (2018); https://doi.org/10.1007/s13410-017-0559-0.

5. A.J. Rani and S. Mythili, J. Clin. Diagn. Res., 8, 108 (2014); https://doi.org/10.7860/JCDR/2014/7603.4121.

6. P. Saha, P. Banerjee, L. Auddya, P. Pal, M. Das, M. Dutta, S. Sen, M.C. Mondal, A. Kumar and U.K. Biswas, Arch. Med., 7, 5 (2015).

7. H.R. Hasan, N.N.A. Aburahma and A.A. Al-Kazaz, Orient. J. Chem., 33, 2776 (2017); https://doi.org/10.13005/ojc/330610.

8. O. Erel, Clin. Biochem., 38, 1103 (2005); https://doi.org/10.1016/j.clinbiochem.2005.08.008.

9. O. Erel, Clin. Biochem., 37, 112 (2004); https://doi.org/10.1016/j.clinbiochem.2003.10.014

10. A. Aycicek and O. Erel, J. Pediatr., 83, 319 (2007).

11. O. Kose, V. Canakci, C.F. Canakci, A. Yildirim, E. Kermen, T. Arabaci and A. Gungor, Oxid. Antioxid. Med. Sci., 3, 153 (2014); https://doi.org/10.5455/oams.040714.or.069.

12. E. Beyazyildiz, A.B. Çankaya, E. Ergan, M.A. Anayol, Y. Özdamar, S. Sezer, M.H. Tirhis, P. Yilmazbas and F. Öztürk, Int. J. Ophthalmol., 6, 531 (2013); https://doi.org/10.3980/j.issn.2222-3959.2013.04.23.

13. R. Naruse, M. Suetsugu, T. Terasawa, K. Ito, K. Hara, K. Takebayashi, K. Morita, Y. Aso and T. Inukai, Saudi Med. J., 34, 135 (2013).

14. I. Cilenšek, S. Mankoè, M.G. Petroviè and D. Petroviè, Dis. Markers, 32, 93 (2012); https://doi.org/10.1155/2012/675628.

15. C. Li, X. Miao, F. Li, S. Wang, Q. Liu, Y. Wang and J. Sun, Oxid. Med. Cell. Longev., 2017, 9702820 (2017); https://doi.org/10.1155/2017/9702820.

16. U.N. Singh, S. Kumar and S. Dhakal, Int. J. Contemp. Med. Res., 4, 1204 (2017)

17. J.S. Oliveira, A.A.N. Silva and V.A. Silva Jr., Braz. J. Biol., 77, 68 (2016); https://doi.org/10.1590/1519-6984.09915.

18. O. Merhan, K. Bozukluhan, M. Kuru, F. Buyuk, Ö. Özden and A. Kukurt, Kafkas Univ. Vet. Fak. Derg., 23, 933 (2017); https://doi.org/10.9775/kvfd.2017.18004.

19. C.Arana, A.M. Moreno-Fernández, G. Gómez-Moreno, C. Morales-Portillo, 
I. Serrano-Olmedo, M.C. De La Cuesta Mayor and T.M. Hernández, Endocrinol. Diabetes Nutr., 64, 258 (2017); https://doi.org/10.1016/j.endinu.2017.03.005.

20. D.C. Guzman, H.J. Olguín, E.H. García, A.V. Peraza, D.Z. De La Cruz and M.P. Soto, Redox Rep., 22, 10 (2017); https://doi.org/10.1080/13510002.2016.1205303.

21. Y. Wu, L. Tang and B. Chen, Oxid. Med. Cell. Longev, 2014, 1 (2014); https://doi.org/10.1155/2014/752387.

22. I.P. Chatziralli, G. Theodossiadis, P. Dimitriadis, M. Charalambidis, A. Agorastos, Z. Migkos, N. Platogiannis, M.M. Moschos, P. Theodossiadis and P. Keryttopoulos, Open Ophthalmol. J., 11, 51 (2017); https://doi.org/10.2174/1874364101711010051.

23. R. Mancino, D. Di Pierro, C. Varesi, A. Cerulli, A. Feraco, C. Cedrone,
M.D. Pinazo-Duran, M. Coletta and C. Nucci, Mol. Vis., 17, 1298 (2011).

24. V.S. Reddy, S. Sethi, N. Gupta, P. Agrawal and R.C. Siwach, Retina, 36, 1049 (2016); https://doi.org/10.1097/IAE.0000000000001042.

25. K. Kirboga, A.V. Ozec, M. Kosker, A. Dursun, M.I. Toker, H. Aydin, H. Erdogan, A. Topalkara and M.K. Arici, J. Ophthalmol., 2014, 1 (2014); https://doi.org/10.1155/2014/820853. 